\title{
The School Effectiveness Research Programme: Towards a Practioners' Perspective in the Latin American CONTEXT ${ }^{1}$
}

\author{
El Programa de Investigación Movimiento de Escuelas Eficaces: \\ Hacia una Perspectiva basada en los Actores en el Contecto de \\ AmÉrica LaTINA
}

Andrés Sandoval-Hernández PhD Student, Department of Education University of Bath Bath, BA2 7AY, United Kingdom A.Sandoval@bath.ac.uk

Juan Carlos Barrón Pastor PhD Student, Research Assistant, Overseas Development Group School of Development Studies, University of East Anglia

Norwich, NR4 7TJ, United Kingdom j.c.barron-pastor@uea.ac.uk

Received: May 7, 2008. Accepted: july 23, 2008

\begin{abstract}
Based on the Lakatos' notion of research programmes, this paper analyses the structure of the School Effectiveness Research Programme as it has been developed mainly in the UK and USA, and reviews the main criticisms that have recently risen, stressing those regarding its adherence to a positivist epistemology and the lack of context-sensitive models for school effectiveness. The paper concludes in outlining some possible basis for a new research programme which would suit better the Latin American social reality. This programme would include shifting towards a more critical epistemology and the use of a methodology and theoretical-conceptual tools that would allow the design of context-sensitive (both, micro and macro contexts) models for school effectiven ess promoting a gradual inclusion of practitioners' perspectives.
\end{abstract}

Keywords: effective schools, Latin America, scientific research programmes, epistemologies based on practitioners' perspective.

Resumen: Utilizando la noción de los programas de investigación científica de Lakatos, este artículo analiza la estructura del Movimiento de Escuelas Eficaces tal como se ha desarrollado en el Reino Unido y Estados Unidos principalmente y revisa las críticas más importantes que se le han hecho en los últimos años, poniendo mayor énfasis en aquellas relacionadas a su afiliación epistemológica positivista y a la falta de modelos de eficacia escolar sensibles al contexto. El documento concluye delineando algunas posibles bases para un nuevo programa de investigación que 
sería más adecuado para las caractenísticas de la realidad social predominante en América Latina (i.e. inequidad social). Dicho programa incluiría el cambio hacia una epistemología más crítica y la utilización de una metodología y de herramientas teórico-conceptuales que permitan el diseño de modelos de eficacia escolar sensibles al contexto social y organizacional de las escuelas promoviendo una inclusión progresiva de las perspectivas de los actores.

Palabras clave: escuelas efectivas, América Latina, programas de investigación científica, epistemologías basadas en la perspectiva de los actores.

\section{INTRODUCTION}

The School Effectiveness Research Programme (SER) has been working for more than three decades on the improvement of education quality. However, SER has received several critiques related to theoretical and methodological issues that have been part of a prolific debate about its boundaries and potentials. The origin and main theoretical and methodological discussions around SER concur with the United Kingdom (UK), the United States of America (USA), (Mortimore et al., 1988; Rutter et al., 1979) and other so-called developed countries, so they correspond to the socio-political and economical contexts of countries with similar education interests. But in Latin America, the socio-political and economical contexts are very different from those where the programme is being designed and debated. Many critiques to SER are related to the controversial conceptualisation of social context and attach those limitations to positivist approaches and to the difficulties in assuming neutrality when the reproduction of inequalities could be reinforced by that supposedly impartial stance (cf. Slee et al., 1998; Thrupp, 1999; Willmott, 1999). Particularly, a key challenge for Latin American programmes is that related to the reproduction of inequalities. In Latin America, education is considered crucial for reproducing as well as for avoiding the reproduction of those inequalities. Moreover, measuring the effectiveness of schools could be particularly sensitive if socio-economic and political contexts are considered, as they have been up to this moment. On the other hand, it can be supposed that Latin American researchers would be very receptive if improving education could consider variables attached to the avoidance of inequalities.

SER is a "line [programme] of research that investigates performance differences between and within schools, as well as the malleable factors that enhance school performance, usually using student achievement scores to measure the latter" (Luyten et al., 2005: 252). In order to achieve a better understanding of those performance differences and their relationships with assessable factors gaining more effectiveness in different contexts, such as the Latin American one, it is necessary to develop theoretical and 
methodological contributions that would enhance their applications and help in the re-examination of those controversial concepts to eventually produce the basis for setting a new research programme which would suit better the Latin American social reality.

This paper aims to participate in the theoretical and methodological debate about SER from a Latin American perspective using the model for the analysis of scientific research programmes proposed by Lakatos (1970). This model explains that this kind of programmes has a hardcore theory that is defended by a protective belt of arguments, and it is subject to heuristic processes where the debate strengthens or weakens the fundaments of the whole research line. The paper discusses some of the critiques and their responses related to epistemological and ontological conceptions of the context used for SER investigations, and proposes some theoretical and methodological aspects for consideration in further research when discussing contextual factors. Emphasis is placed on those critiques that consider SER as essentially positivist to propound an alternative approach that would respond more adequately to Latin American preoccupations, such as the necessity of adapting schools for reducing inequalities effectively. The idea is to keep some medullary aspects of SER's hardcore and at the same time to change some aspects of its positivist tradition into a more critical comprehension of the social context.

The general formulation that is proposed here for guiding further SER investigations in Latin America and which eventually suggests a new basis for approaching contextual factors of the research programme will be based on the original stance SER triggered: school matters. It needs to be underlined that school cannot be separated from its context. Therefore, context is not an external reality to school as it has been considered in previous theoretical debates.

It seems obvious that one of the prerequisites for the usefulness of applied research is that its results should be obtained by analysing the reality in which improvements are to be implemented. That is to say that if we want to make SER useful for Latin American countries, it is necessary for this research to be tailored for the Latin American schools and their characteristics (Murillo, 2003).

Worldwide, and particularly in Latin America, there is the common necessity for promoting more equal contexts and the important role that can be played by schools in precluding or reinforcing inequalities, as it is important in terms of people's access to and management of information, financial resources and remittances. It is not an option to ignore education necessities due to the 
contextual inequalities (Brunner, 2000) but to go for a meaningful democratisation of education policies (Gundara, 2000), and to "unmask and deconstruct the apparent neutrality of civism - that is, the supposedly universal, neutral set of cultural values and practices that underpin the sphere of the nation-state" (May, 1999: 30).

The transfer of findings to educational systems in Latin America is very questionable when taking into account the complexity of difficulties experienced in many of these societies. The general lack of adequate social and educational infrastructures, the fact that many people still live at a subsistence level, where families are forced to relay on child labour as a necessary means to fulfil their basic needs; the historical forms of inequalities and the way they intersect with post-colonial underdevelopment are some examples of the present characteristics in many countries in the region (Rassool and Morley, 2000). Without disdaining what can be learnt from the research conducted in Europe and North America, it is necessary to evaluate what parts of it can actually add to the solution of the Latin American issues and what must be developed from the analysis of our own reality.

Basing on what has been mentioned above, in order to help SER to reach its objectives in the Latin American context, special interest must be given to determine, explain and compare the inequity patterns in the education systems.

The structure of the paper follows the Lakatos' model starting with a brief explanation. Then, SER hardcore is presented using the rational reconstruction ${ }^{2}$ of the mainstream tradition of SER proposed for that purpose by Lauder et al. (1998). After that, the paper tracks some critiques to SER related to its positivist approach and its lack of a plausible incorporation of contextual factors. The fourth section briefly introduces some arguments presented by Teddlie and Reynolds (2001) to defend and enhance SER's theoretical and methodological scopes. The heuristics of the paper proposes some reflections on both theoretical and methodological stances about considering contextual factors from a critical perspective and at the same time maintaining some of the SER's hardcore elements related to the role played by schools. In the conclusions we make a final analysis of the SER's debate and present our position on it.

\section{LAKATOS' MODEL FOR THE ANALYSIS OF RESEARCH PROGRAMMES}

According to Lakatos (1970), a research programme consists of three main parts: a hardcore, a protective belt, and a positive and negative heuristics. The hardcore consists of very general hypotheses that give the research programme 
its essential characteristics and bedrock assumptions. The protective belt is a set of auxiliary theories underlying and protecting the hardcore from falsification, although part of the research programme can be changed or adjusted as a result of anomalies or empirical challenges without abandoning the programme itself. The heuristics (positive and negative) is a set of rules or hints about how to treat the hardcore and the protective belt in order to aid discovery or invention. The negative heuristics states what the scientists are advised not to do, for example, that the hardcore of the programme should not be abandoned or modified. On the other hand, the positive heuristics specifies what scientists should do within the programme - what issues they should address, in what order - to change or adjust the protective belt.

The major indication of the merit of a research programme, according to Lakatos, is the extent to which it leads to confirmed predictions or explanations. In this way, a progressive research programme is the one which remains coherent between its hardcore and protective belt and which eventually leads to new predictions or explanations, whereas a degenerating research programme is the one that loses its coherence and/or is not capable of leading to innovative predictions or explanations.

\section{THE HARDCORE OF SER}

According to Lauder et al. (op cit, : 52-53), a rational reconstruction of the mainstream tradition of SER would be as follows:

1. School as organizations do have an effect on students; do influence students' examination performance, contrary to the view that it is the teacher rather than the school who has effects on students' performance, or to the view that when contextual factors are fully taken into consideration there is no significant difference among schools.

2. These school effects are not caused by chance and the effects that improve school performance in relation to examination success can be engineered on the basis of SER.

3. Schools are like any other organization where staff and children will respond to the systems, sanctions and rewards of a school so that successful re-engineering is possible.

4. Schools as organizations are structured as nested organizations. For example, their central/local government serves as the broadest organizational structure within which there are different schools, 
departments, classrooms, etc. It is further assumed that schools' effectiveness can be identified by the analysis of the performance of each level and by the inference of the effectiveness of the relationship among all the levels.

5. There is a degree of relative autonomy among levels and between the education system and society. Therefore, schools can generate effects independent of many of the factors external to the school that may impinge on examination outcomes.

\section{SOME CRITIQUES POSED AGAINST SER}

There has been a long debate within SER and a vast debate among critics and defenders of this programme, which would deserve a whole paper on its own. Fortunately, there are some outstanding compilations of criticisms and counter-criticisms. Among the criticisms, what stands out are the books of Slee et al. (1998) and Thrupp (1999). As for the counter-criticisms, Teddlie and Reynolds (2001) wrote an exact standoff of fourteen points in defence of SER. Luyten et al. (2005) is another document mentioned throughout this paper as it is a recent work that confronts critiques and recommendations related to this issue. This paper, as it has been previously stated, will be focused exclusively on those aspects of the debate related to the alleged positivist stances of SER and to the problems related to gaining a plausible consideration of contextual factors in it.

Several authors strongly criticise SER because of its positivist orientation and argue for a more conceptual framework and for the need to overcome what they call the empiricist practice of SER (Wyatt, 1996). These arguments are generally based on SER's staple diet based on observable and measurable indicators or factors (Willmott, 1999) and its limited perspective of the complex relationships between schools and their contexts (Thrupp, 1999).

The critics point out that SER's commitment to positivist methodology necessarily entails a simplistic cause-effect approach to the study of effective schools, since positivism denies that social reality is differentiated and structured, therefore it deals only with constant conjunctions of observable events (Willmott, 1999). As already mentioned, one of the main objectives of SER is to establish or identify malleable (measurable) factors that enhance school performance. These factors are obtained by analysing sets of correlations between directly observable and measurable factors, so the factors with correlation with high school performances can be certainly said to be associated with school effectiveness, but not to cause it, as some SER researches assume. 
This kind of argumentation is said to be based on 'technist' literature which lacks a critical perspective on the relationship between schools and their social and political contexts (Thrupp, 1999).

Another point that has been emphasised is the essential atomist ontology that positivism presupposes. From this point of view, it is almost impossible for SER to see society as a whole as it has many limitations to recognise the agency of the school itself and the actors who constitute it (Willmott, 1999). The school is not an indivisible subject; it is an agent built by several actors that have agency as well. The Human-based perspectives that presuppose that people are passive sensors of given facts entail individualist explanations of society (Bhaskar, 1979). In Latin America, such explanations are even more difficult to be perceived as convincing as this region of the world is widely known as 'collectivistic' (Oxhorn, 2000). Atomist perspectives tend to derive from analytical dualisms where the structure and the agency are presented as irreducible dichotomies (Archer, 1995; Archer, 1996; Layder, 1997), such as the school context is. Some authors have suggested a Cartesian dualism approach to explain certain interdependency and at the same time to recognise their distinctive properties (Willmott, 1999). But these phenomenological approaches can face problems when considering society as having a complex nature linked to power relations (Gonzalez-Casanova, 2004).

A good example for exposing the problems of this approach can be found precisely in the notion of school climate. This is a key concept in the protective belt of SER that allows a wide range of factors to be identified with school efficiency, organised around a notion that supposedly gives some cohesion to the ingredients of the 'recipe' to keep them together (Lauder et al., 1998). The cohesive notion of climate admits that it can vary across schools, and it is also admitted that it can influence the role of teachers and students; yet there is no theory that explains how it is created or how it interacts with actor's performance (Lauder et al., 1998). Take for example that a good school, according to these authors, may be found to have high expectations of its students; but those high expectations may be a result of having a good student intake over a number of years who are likely to produce good results (Davies, 1997). Another hitch that can be seen in the notion of climate, which is commonly seen for other concepts used by SER, is that usually it has been defined by an arbitrary selected set of items in a questionnaire that varies greatly among different studies (Miller and Fredericks, 1990).

Critical authors have demonstrated that resembling contexts, as constructed, makes its understanding more accurate. According to these criticisms, to attend the problem it is necessary to move the analysis to a more conceptual level 
which considers unobservable mechanisms - like many contextual factors- to explain observable phenomena - like inequalities (Lauder and Brown, 2007).

\section{SER'S PROTECTIVE BELT}

This section of the paper is mainly based on the article written by Teddlie and Reynolds (2001) to address the criticisms of SER contained in two books: Slee and Weiner with Tomlinson (1998) and Thrupp (1999). The format of the paper is in the 'Point: Counterpoint' style and presents a series of 14 criticisms of SER followed by the counterpoints, which range from simple statements of agreement to vigorous defences.

Teddlie and Reynolds ( $\mathrm{T} \& \mathrm{R}$ ) claim that criticisms against SER have been political, methodological, and theoretical. They tacitly present SER as politically neutral as the political criticisms come from very different directions. Methodological criticisms are presented mainly as internal debates of the field and it is said that many of them have been muted by recent methodological developments. Finally, they concur with the criticisms regarding the lack of theoretical bases; however, they address the current efforts to attend this 'perennial' problem. For this paper, as it has been said, we are going to review only the points concerning the argued positivism of SER and its alleged incapacity to consider the context in an appropriate way.

T \& R widely justified that context factors "are deemed important by SER researchers" (2001:58); they cited several studies that have been explicitly considering context variables within SER since the field began, and they also mentioned that there are even subfields of the study of context factors within SER.

Nonetheless, instead of recognizing the debate as a recurrent struggle, as Thrupp and other critics would perceive the discussion around context, T \& $\mathrm{R}$ prefer to present the debate as a proof of a full discussion around the concept. The evidence presented in defence of SER makes it clear that the context has been doubtlessly taken into consideration by many of the SER researchers. Moreover, they also comment in some detail on a number of the elements considered when performing 'context analyses' in a previous work conducted by Teddlie and Stringfield (1993). The quality of the research design used in this work is noticeably superior to many earlier and recent efforts in the field. Although the arguments presented by $\mathrm{T} \& \mathrm{R}$ correctly address the critiques, they do it only up to a certain point. It is clear that the kind of work cited by $\mathrm{T} \& \mathrm{R}$ to confront the critique regarding to the lack of contextually sensitive models in SER is not a common thing in the programme; and that 
for the SER researchers, concerned about designing context sensitive models, there is still much to learn about the mechanisms underlying and constituting what it is known as context; and about what can be done to eradicate the effect that unfavourable contexts impinge on school performance.

It is important to mention that for authors who assume very different perspectives, including critics and defenders, qualitative research is indispensable when seriously thinking about considering the context for school effectiveness models. That is to say that SER would benefit from more qualitative research by getting data more suitable to understand the complex reality in which schools are submerged, and thus useful to generate theory within the field (Lauder et al., 1998; Riddel et al., 1998; Teddlie and Reynolds, 2001; Thrupp, 1999). In any case, they both agree that studies would not be able to approach the problematic notion of context if they go on perceiving it as an external reality.

Now, regarding the alleged positivism of SER, even though $\mathrm{T} \& \mathrm{R}$ admit that some SER researchers work under the positivist paradigm, they disassociate themselves from (post)positivist traditions, affirm that they have assumed a pragmatic position, and explicitly claim that their research has the following orientations:

- Inclusion of both quantitative and qualitative methods for gathering and analysing data;

- Use of both deductive and inductive logic depending on the phase of the research project;

- Use of both objective and subjective epistemological approaches depending on the data being worked with;

- An axiology in which values play a large role in interpreting results;

- An ontology that accepts external reality, yet denies that truth can be determined once and for all.

They also argue that Pragmatism is a philosophical orientation valid for the study of schools just as Critical Theory (approach used by the critics). Once again, it is not arguable that there exist some works using philosophical orientations and methodology that allow to better identify and understand those factors that enhance school performance, but what is needed is a more constructive discussion and proposals that would lead to the consolidation of a whole methodology that takes the programme a step further in reaching the goal of improving education. 


\section{HEURISTICS}

Up to this moment, the paper has sketched off the hardcore of SER and part of its protective belt related to some of its theoretical and methodological limitations concerning the conceptualisation of the context. In this section, the paper aims at outlining some hints about how to treat the protective belt in order to strengthen (when possible) the hardcore of SER. The heuristics proposed in this paper tries to avoid those contradictions that attach positivist limitations to the programme at the same time as its application in a Latin American context is considered.

First, it has to be stated that the hardcore elements that must not change are: that schools as organizations do have an effect on student outcomes and that the effects that improve school performance can be obtained on the basis of SER by having units of analysis that allow schools to recognise and develop their internal effectiveness. Then, it is important to make clear that our starting points are: i) that school is not isolated from its context; ii) that education is fundamental in perpetuating or restraining inequalities; iii) that behaviourist schemes of sanctions and rewards cannot be the basis for initiatives aiming to enhance the effectiveness of education (Lauder et al., 1998): and iv) that even when, for convenient purposes, schools can be seen as nested organisations that can be simplistically yet practically evaluated, schools are historical complex systems and "the configuration [of this kind of systems] is organised through the inter-definition and interaction of relations and conjuncts of relations" (Gonzalez-Casanova, 2004: 99) of all the actors involved.

Critical theorists would agree with Teddlie and Reynolds about changing schools, as they currently exist. But towards which direction should schools change? Who should state that direction? How should the effectiveness of those schools directed to better societies be assessed? We agree that school change is possible within the existing socio-political systems as they exist, but at the same time we acquiesce to critical theorists that social justice and equity must be a guide that defines the parameters of SER, especially in countries such as the Latin American ones, where the reproduction of inequalities is not only a big problem of injustice and of violation of human rights but also it can become a problem of peace and security for the entire region.

As it has been reviewed here, the positivist approach might be too tight for SER. Its researchers are continuously struggling with the concept of context and several of their critics, such as Thrupp (2000), have pointed out that the problem of the positivist scope is the theoretical explanation of the SER's 
apparent incapacity to give plausible concepts of contextual factors. The response to the critics has been that any philosophical orientation is valid for the study of the schools, and it might be true, but the problem is that certain things can be explained better and in a more useful way by means of different philosophical lens. For example, in the notion of context, the problem seems to constitute the remains of the conception that the nature of things is an external reality. The problem of giving context this ontological position is the main argument that this paper constrains of SER's mainstream. School and context are intrinsically related. To develop this point, three lines will be followed: i) the problem of reifying concepts; ii) the problem of the agency of practitioners; and iii) the problem of giving school communities the power of defining and assessing their contextual factors and keeping generalisable units of analysis.

The problem of reifying concepts. 'The idea of 'reification' refers to the mental process of making something fixed, or thing-like, when in reality it is the outcome of a particular kind of social relationship" (How, 2003: 63). That is what happens with the notion of context. A very common manner to reify is considering two abstract notions and establishing dichotomies for that. In this case, school and context are both conceptual entities and are referred to their inter-definition, interaction of relations, and conjuncts of relations that constitute those conceptual entities. If there is an original cause, it is not relevant in complex systems, where if one point is affected the whole system will be affected somehow (Byrne, 1998). The actors that constitute the school, and the school itself, have inter-definitions and interactions with the actors that shape what is called context. This is a concept used to make sense and keep manageable some aspects of reality.

Schools and contexts are both complex systems in interaction and it is possible to improve the performance of one of the systems (the school) that affects and is affected by another system (the context). These systems are differentiated for epistemological purposes. They are not really a dichotomy as they are conceptual entities. Deleuze and Guattari DIN(1972) employed the allegory of the rhizome to explain a mode of 'underground' organisation that precedes the conceptual entity avoiding binary simplifications. A good example to have an image of a rhizome is to observe the roots of grass. It is impossible to know which root corresponds to which grass, but each grass has roots and all are interconnected. According to Deleuze and Guattari, those multidimensional networks lie under the surface of all conceptual entities; thus, the school and its context would share rhizomatically many factors such as the reproduction of inequalities. This point of view could essentially agree 
to different approaches to explore the reproduction of inequalities in education, such as those of Bourdieau, Ball, etc.

What seems crucial is the trust that SER's authors can have on actors' agency. Is the context something fixed and outstanding of actors reach? Or is it something that can be reached by the persons that constitute what we call schools? The main element of SER's hardcore is that school matters. Education researchers, actors, policy makers and in general anyone concerned about education, cannot wait for the transformation of the whole social world or for a discussion of priorities of recognition or redistribution for other contexts. Researchers and school communities have agency. We all have to work on it now with the existing socio-political systems. We all have to recognise that we, as part of the context, are not entirely independent from schools. One thing that we can do is to work within schools to push out contextual transformations. School is part of the context and so are the members within the schools. The good news is that this agency can start at any point and school communities seem to be a good agent to do it.

How good can it become? How effective can it be? Using this argument, work can be done assuming that the nature of school is always becoming, and it does not deal with context as an external reality but as a human artefact that can potentially reproduce and transform reality by transforming itself.

But as Deleuze and Guattari advised, the determinations of conceptual entities -such as school, context and effectiveness- are coded by power because, among other explanations, those who are powerful feel legitimacy to the construction of identities and the interpretation of the desires of those on whom they exert hegemony. Thus, if researchers use interpretative approaches they might be reproducing those dynamics that supposedly they are pretending to avoid. This leads to the second problem, the problem of the agency of the practitioners.

The problem of the agency of practitioners (strengthening practitioners). It is fundamental to underline that construction of identity is a process that is always produced in relation to others, and that stereotypes can be attached to processes of reproduction of inequalities (Barrón-Pastor, 2007). Homi Bhabha alerted that "an important feature of colonial discourse is its dependence on the concept of 'fixity' in the ideological construction of otherness" (Bhabha, 1994: 66). This 'fixity' is basically a stereotype, the construction of identity not by the other, but about how dominant discourses construct those supposed 
identities, where the 'ours' usually have positive connotations and the 'others' are often associated with negative values.

Defining the practitioners in schools can follow this process of stereotyping if we do not turn to the actors to identify and refer to themselves. Legitimating processes passes by fixing identities through the ideological construction of otherness (Bhabha, 1994). Interactions would reinforce inequalities if 'experts' construct the problem, debate about it and determine a diagnostic and a solution without considering those who are being affected by those dynamics. In one of the previous works, one of us concluded that 'problematisation' of the 'others' could be a 'superior stage of stereotypes' in very elaborate ways (Barrón-Pastor, 2006). It is necessary to examine through research if the breakage of stereotypes can be reached through deepening interaction (BarrónPastor, 2007), and whether this interaction can be a dialogue or not if the communicative action is subdued to dominant rationality (Irigaray, 2002).

Thus, dominant cultures establish diagnostics about how schools should be and how important the context is according to their own cultural references. But this might not apply to other cultures. In this line, because SER establishes the terms of effectiveness of schools, this research programme is being under fire since it is alleged that the problems and contexts are defined by a dominant power that claims neutrality to be able to continue reproducing those dynamics (Thrupp, 1999). Deleuze and Guattari (1972) explained a basic dynamic of stereotyping with the Anti-O edipus argument; in short, this argument explains that it is not the psychotic child who wants to replace the father, but it is the paranoid father who sees a rival in the child. The father (the powerful) is the one who defines the social context, not the child (the powerless).

For Latin America it is possible to propose this theoretical inversion. Latin America does not pretend to substitute the paranoically developed education systems that reproduce those models where they are always on the top. Latin America would pretend to coexist in a different way, according to its context and actors. It would be very probable that most of Latin American authors agree that avoiding the reproduction of inequalities is a priority, and that a crucial necessity of schools is to develop tools to do it the most effectively they can. It seems that if we approach the notion of context as an external reality for schools, what we may be also doing is reproducing those dynamics that reinforce inequalities instead of using schools as ways of prevention for those undesirable dynamics.

Similarly, practitioners are not going to usurp researchers' jobs. It is almost sure that they want more effective schools to solve those problems that the 
actors construe as affecting their specific contexts. Researchers want to avoid interpretation and "teachers [not only teachers, but all practitioners] are perfectly capable of generating their personal theories by systematically studying their practice" (Whitehead and McNiff, 2006: 21). But how are we going to compare systematically such different contexts? This takes us to the third problem mentioned above, the problem of giving school communities the power of defining and assessing their contextual factors and keeping generalisable units of analysis.

The problem of giving school communities the power of defining and assessing their contextual factors and keeping generalisable units of analysis (SER from practitioners' perspective). To continue the argumentation in this paper, it has to be stated that it is important to remember that inequalities are reproduced by complex power dynamics (Gonzalez-Casanova, 2004) and that to avoid stereotypes it is necessary to allow the practitioners to define themselves, as they are the most familiarised with educational practices. Smith (1998) suggested that practitioners should state the goals and changes to be pursued in schools after some education programmes (and we can add that these programmes could be assessed too). In the same line, Luyten et al. (2005) suggested including school-performance feedback systems to provide schools with systematic feedback of their performance in comparison with other schools. Furthermore, currently the Children as Decision Makers Academic Group 3 intends to study how children and students_can actively participate in decision making in schools.

But how are we going to recognise the agency of practitioners if the research programme excludes them from goal stating, achieving, and evaluation processes? If SER wants to be part of the debate and the efforts to struggle against inequalities reproduction, it seems that it has to promote participation and diminish exclusion of all the actors within schools. By promoting the participation of all actors we can gain parameters to see at least if schools show efficiency in promoting agency, which is widely considered as an element of freedom; or to follow some authors such as Michele Scweinsfurth (2007), which has overcome some difficulties in comparing the education for global citizenship in very different contexts; or Rao and Robinson-Pant (2006) that have entirely devolved the voice to practitioners when approaching crosscultural perspectives.

Is it possible to design models of school effectiveness taking into account all practitioners? We think that it is possible. This big challenge has to be addressed by a mix-model approach, as qualitative and quantitative approaches have to complement each other in order to obtain the desired results. On the 
one hand, qualitative research can contribute to a deeper understanding of many of the variables related with the school effectiveness (especially those concerning the so-called contextual factors) and the mechanisms that cause and underlay them (as the power dynamics). On the other, quantitative models are easily reproducible in wide scales and they are essential to establish comparable units of analysis. A first step is to recognise, as critics and defenders of SER agree, that there is a necessity of SER to strengthen their qualitative tools in order to have better units of analysis that would allow schools to define efficiency parameters and that would produce information more suitable to build the theoretical basis of the programme. Action Research could be a useful tool to involve actors in the research process. From the categories of those researches we could establish some units of analysis and to see from a practitioner's perspective how inequalities and contexts are being affected by the action of schools.

Action Research is a community-based technique that allows capacity building for all participants, "acknowledges the limitations of the knowledge and understanding of the 'expert' researcher, and takes into account the experience and the understanding of those who are centrally involved in the issue explored- the stakeholders" (Stringer, 2007: 235). In his vast production, Jack Whitehead has demonstrated that practitioners can investigate their own practice, produce their own explanations that can be constantly tested by the critical responses of others, and gain validity by "showing the authenticity of the evidence base, explaining the standards of judgement used, and demonstrating the reasonableness of the claim" (Whitehead and McNiff, 2006: 98).

However, some SER's authors could claim that giving practitioners the power to define contextual factors and to assess their changes would result in such different variables that it could be impossible to analyse or compare them. But producing qualitative data is a common form to create categories for further quantitative research (Bryman, 2004), and, following Habermas (1987), practitioners can be aware from the beginning of sharing some agreements to reach inter-subjective understandings aiming to share some units of analysis and to discuss those factors that are difficult or polemic to be categorised into the agreed units of analysis.

Trusting practitioners' agency and interests, and sharing the responsibility in establishing the validity of variables and its potential correspondence to the units of analysis could give SER a new breath and insert the programme in current debates about inequalities and poverty reduction through education. The capabilities approach of Sen, the human flourishing of Nussbaum or the 
Latin American perspectives such as the critical widening look of Boltvinik or the complex equality dimensions of Ottone, or many other approaches could give some traces of the different perspectives that school effectiveness can gain if it participates in a potential debate about effective schools for promoting equality.

Besides, the job of creating preliminary units of analysis is not starting from zero. In Mexico, for example, there are some recent efforts to link the effectiveness of education to those policies focused on poverty reduction (Flores-Crespo and De la Torre, 2007). As previous studies have demonstrated, the current policies to fight poverty have not produced positive results in academic achievement even if they are a good instrument to raise school enrolment and attendance levels (Muñoz-Izquierdo and Villarreal, 2005; Sandoval-Hernández, 2007; Sandoval-Hernández and Muñoz-Izquierdo, 2004).

Now, it is very important to recognise the limitations of SER related to social inequalities. Although it is undisputable that schools play a very important role in undermining or reinforcing inequalities, it is true that in general schools or education systems cannot be the only responsible units for the social inequality. It has to be clear that according to the SER definition and goals, what schools can be held responsible for is to reach equality in the distribution of opportunities to get equal schools outcomes among different groups of students. It is highly possible that by reaching this objective a contribution to diminish the social inequality is made; but this issue is beyond the scope of SER.

Equality in education has at least four dimensions: i) Equality of access and retention, which refers to the notion that every child has access to education and every child who wishes to stay in education is not prevented from doing so due to economic disadvantage, for example. ii) Equality of learning environment, which considers the idea that all individuals enjoy equivalent learning conditions (for example, lack of gender bias in the curriculum) iii) Equality of school outcomes, which is related to the idea that all students master skills or gain knowledge designated as goals of the education system in which their educational success does not depend on the social, economic and cultural position of their families. iv) Equality in using the results of education, which is the highest stage and concerns the idea that once students have left the education system, individuals or groups of individuals have the same chances of using their acquired knowledge and skills in employment and wider community life. 
As we know and as it is defined within the programme by the researchers, from the dimensions of equality previously described, SER is located in the third one. It is indubitable that equality is a basic element of the concept of school effectiveness. A school that is differently effective (in the sense that it is 'better' for some students than for others) is not an effective school but a discriminatory one. It is simple; there cannot be efficacy without equality (Murillo, 2003). Nonetheless, what is important is to focus on those aspects of equality in which SER can realistically contribute, namely, the equity in school outcomes.

\section{CONCLUSIONS}

From the analysis of the arguments presented in this paper it can be inferred that:

i) There are at least three positions on the SER debate. For practical reasons we will call them the Mainstream, whose bedrock assumptions are outlined in the hardcore section; the Critical approach represented by the critics of the SER and whose arguments can be found in the sections of critiques; and the Pragmatist approach represented by the researchers working within the SER programme and whose arguments are presented in the protective belt section.

ii) According to the criteria for the evaluation of research programmes contained in the framework developed by Lakatos (i.e. the capacity to remain coherent between its hardcore and protective belt and to eventually lead to innovative explanations), the SER programme cannot be considered as a progressive one. Therefore, a movement towards a new research programme is needed in order to address the main objectives originally set for SER.

iii) The current alternatives are the ones offered by the Pragmatist and the Critical Realist approaches.

The debate is far from its end and, as Teddlie and Reynolds admit, it is unclear what value a further dialog will bring. However, through the paper we state our agreement and disagreement with different points postulated for each of them and also we raise attention to three problems that have to be dealt with in order to make it possible to produce a new research programme more suitable for the Latin American context. 
This paper emphasises the necessity of avoiding reification and proposes to adopt Deleuze and Guattari clarification of reality using the rhizome to explain those aspects of reality that are distinguishable but complexly related to one another and to the implicated power relations. Using this approach, the nature of school is always in the state of becoming, and it does not deal with context as an external reality but as a human artefact that can potentially reproduce and transform reality by transforming itself.

The main argument presented is that SER is essentially committed to equality but it is necessary to strengthen practitioners' participation to avoid interpretation and reproduction of dynamics of inequality when applying the programme. As practitioners are real experts, they can examine their own practice, produce their own explanations, discuss their arguments, and be seriously considered in the definition of school effectiveness. Thus, the central proposal of the paper is to discuss and to apply SER from practitioners' perspectives.

We strongly believe that we, as practitioners in education, cannot wait for the conclusion of the debate and then try to import and adapt the winning research programme to the Latin American context. If we want to move towards the improvement of our schools and education systems, we must participate in the debate and, at the same time, generate theoretical-conceptual tools from our own perspective and according to our interests and priorities, and keep on working to produce a sound basis for setting a new research programme which would suit better the Latin American social reality.

\section{NOTES}

1 Both authors thank for the comments given to this paper by Hugo Lauder and Kasia Kawalec; we are also grateful to the Consejo Nacional de Ciencia y Tecnología CONACyT (Mexico), because of the financial resources that made this collaboration possible.

2 The term of rational reconstruction was coined by Lakatos (1970) and refers to a reconstruction of what the researchers have logically and historically been committed to, independently of their own thinking, that is to say that it is not necessarily related to the researchers' personal commitments and to what they believe (Lauder et al., op cit).

3 More information can be obtained from http://www.childrenasdecisionmakers.org/ 


\section{BIBLIOGRAPHIC REFERENCES}

Archer, M., 1995

Archer, M., 1996

Barrón-Pastor, J. C., 2006
Realist social theory: The morphogenetic approach. Cambridge University Press, Cambridge.

Social integration and system integration: Developing the distinction. In: Sociology, 30(4): 679-699.

Constructing problems and solutions for indigen ous peoples: A Critical discourse analysis about identity and cultural violence in Mexican main political platforms. Dissertation submitted to the School of Development Studies of the University of East Anglia in part-fulfilment of the requirements for the degree of Master of Research in Development Studies. Available at: http:// juanchobarron.googlepages.com (Accessed on August 23rd, 2007).

Barrón-Pastor, J. C., 2007 Promoting intercultural relations? Racism and affirmative actions for indigenous persons in Mexican higher education. Presented at the Society for Latin American Studies Annual Conference 2007. University of Newcastle, Newcastle upon Tyne. The final version is in Spanish and it is a forthcoming publication in TRACE Journal. A draft in English is available at: http://juanchobarron.googlepages.com (Accessed on August 23rd, 2007).

The location of culture. New York: Routledge.

The possibility of naturalism. A philosophical critique of the contemporary human sciences. The Harvester Press, Brighton, Sussex. 
Brunner, J. J., 2000

Bryman, A., 2004

Byrne, D., 1998

Davies, L., 1997

Deleuze, G. and

F. Guattari, 1972

Flores-Crespo, P. and

R. De la Torre, 2007

Gonzalez-Casanova, $\mathbf{P}$., 2004

Gundara, J., 2000

Habermas, J., 1987

How, A., 2003

Irigaray, L., 2002
Globalización y el futuro de la educación: tendencias, desafíos, estrategias. Seminario sobre Prospectiva de la Educación en la Región de América Latina y el Caribe. UNESCO, Santiago de Chile.

Social research methods. Oxford University Press, Oxford.

Complexity theory and the social science. An introduction. Routedge, London

The rise of the school effectiveness movement. In: J. White and M. Barber (Eds.). Perspectives on School Effectiveness and School

Improvement. Institute of Education, London.

Anti-Oedipus: Capitalism and schizophrenia. (R. Huxley, M. Seem \& H. Lane, Trans.). Viking Press, New York.

Adopting the human development idea: Lessons drawn from some poverty reduction initiatives in Mexico. Presented at the International Conference of the Human Developmentand Capability Association 2007. Mexico City.

Las nuevas cien cias y las humanidades. De la academia a la política. Anthropos, Barcelona.

Interculturalism, education and inclusion. Paul Chapman Publishing, London.

The theory of communicative action (T. McCarthy, Trans.). Polity, Oxford.

Critical theory. Palgrave McMillan, London. The way of love. Continuum, London. 
Lakatos, I., 1970

Lauder, H. and C. Brown, 2007

Lauder, H., I. M. Jamieson \& F. Wikeley, 1998

Layder, D., 1997

Luyten, H., A. Visscher, \& B. Witziers, 2005

May, S., 1999

Miller, S. and

J. Fredericks, 1990

Mortimore, P.,

P. Sammons, L. Stoll,

D. Lewis \& R. Ecoh, 1988
Falsification and the methodology of scientific research programmes. In: I. Lakatos and A. Musgrave (Eds.). Criticism and the growth of knowledge. Cambridge University Press, Cambridge, pp. 91-195.

An appraisal of competing research programmes on school effectiven ess and school improvement. Working paper.

Models of effective schools: Limits and capabilities. In: R. Slee, G. Weiner \& S. Tomlinson (Eds.). School effectiven ess for whom? Challenges to the school effectiven ess and school improvement movements. Falmer Press, London. pp. 51-69.

Modern social theory. Key debates and new directions. UCL Press, London.

School effectiveness research: From a review of the criticism to recommendations for further development. In: School Effectiveness and School Improvement, 16(3): 249-279.

Critical multiculturalism and cultural difference: Avoiding essentialism. In S. May (ed.), Critical multiculturalism: Rethinking multicultural and antiracist education. Falmer Press, London. pp. 11-41.

The false ontology of school climate effects. In: Educational Theory, 40(3): 333-342.

School matters: The junior years. Open Books, Wells. 
Muñoz-Izquierdo, C. and G. Villarreal, 2005

Murillo, F. J., 2003

Oxhorn, P., 2000

Rao, N. and A.

Robinson-Pant, 2006 2000

Riddel, S., S. Brown \& J. Duffield, 1998
Rassool, N. and L. Morley,

Un marco referencial para interpretar los efectos educativos de los programas compensatorios. Paper presented at the Research Conferenece: Poverty and poverty reduction strategies: Mexican and international experience. Monterrey, México.

Una panorámica de la investigación iberoamericana sobre eficacia escolar. In: Revista Electrónica Iberoamericana sobre Calidad, Eficacia y Cambio en Educación, 1(1). Available at: http://www.ice.deusto.es/rinace/reice/ vol1n1/ Murillo.pdf (Accessed on August 23rd, 2007).

Social inequality, civil society and the limits of citizenship in Latin America. El Colegio Mexiquense, México.

Adult education and indigenous people: Addressing gender in policy and practice. In: International Journal of Educational Development, 26(2): 209-223.

School effectiveness and the displacement of equity discourses in education. In: Race Ethnicity and Education, 3(3): 237-258.

The utility of qualitative research for influencing policy and practice on school effectiveness.

In: R. Slee, G. Weiner \& S. Tomlinson (Eds.), School effectiven ess for whom? Challenges to the school effectiveness and school improvement movements. Falmer Press, London, pp. 170-186.

Rutter, M., B. Maughan, Fifteen thousand hours: Secondary schoolsand P. Mortimore \& J. Ouston, their effects on children. Open Books, London. 1979 
Sandoval-Hernández, A., 2007

Sandoval-Hernández, A. and C. Muñoz-Izquierdo, 2004

Slee, R., G. Weiner \&

S. Tomlinson (eds.), 1998

Smith, L. M., 1998

Stringer, E. T., 2007

Teddlie, C. and

D. Reynolds, 2001

Teddlie, C. and

S. Stringfield, 1993

Thrupp, M., 1999
La equidad en la distribución de oportunidades educativas en México. Un estudio con base en los datos del EXANI-I. In: Revista Electrónica Iberoamericana sobre Calidad, Eficacia y Cambio en Educación, 5(1): 22-42. Available at: http://www.rinace.net/arts/vol5num1/ art2.pdf. (Accessed on August 23rd, 2007).

Equidad y eficacia en la distribución de oportunidades de acceder a la educación media. In: F. Tirado (Ed.), Evaluación de la Educación en México. (pp. 193-247). México: CENEVAL. Available at: (Accessed on August 23rd, 2007).

School effectiven ess for whom? Challenges to the school effectiveness and school improvement movements. Falmer Press, London.

A kind of educational idealism: Integrating realism and reform. In: A. Hargreaves, A. Lieberman, M. Fullan \& D. Hopkins (Eds.). International handbook of educational change (Vol. 5, pp. 100-120). Kluwer Academic Publishers, Dordrecht/Boston/London.

Action research. Sage, London

Countering the critics: Responses to recent criticisms of school effectiveness research. In: School Effectiveness and School Improvement, 12(1): 41-82.

Schools make a difference: Lessons learned from a 10-year study of school effects. Teachers College Press, New York.

Schools making a difference: Let's be realistic!: School mix, school effectiveness, and the social limits of reform. Open University Press, London. 
Whitehead, J. and

J. McNiff, 2006

Willmott, R., 1999

Wyatt, T., 1996
Action research living theory. Sage, London.

Structure, agency and school effectiveness:

Researching a 'failing' school. In: Educational Studies, 25(1): 5-18.

School effectiveness research: Dead end, damp squib or smouldering fuse? In: Issues in Educational Research, 6(1): 79-112. 